\title{
Introduction
}

\section{Philip McCann}

The most obvious conclusion that can be drawn from observations of the geography of industrial production is that space is not homogeneous. In other words, different economic activities take place in different locations. Understanding why this is the case, and explaining exactly how industries are organized spatially, is the central issue of interest in industrial location economics and industrial geography. Over the last decade there has been a general renewal of interest in issues concerning the location behaviour of firms and industries. This renewed interest has not been confined to the academic and research worlds, but has also pervaded many private sector business and public policy spheres. The widespread nature of this revival of interest can be attributed to two different influences, one academic and the other institutional. First, certain key influential authors, such as Paul Krugman and Michael Porter, have highlighted the importance of geographical behaviour for both economics and business analysis. Their work has brought to the attention of a wider audience, previously largely unaware of the significance of these issues, the importance of location questions for a variety of different research fields. Second, institutional changes in international political environments have forced both business and public policy decision-makers to consider the locational aspects of industry at a more explicitly local level. The reasons for this are primarily connected with the development of areas of free trade and free factor mobility, such as the European Union (EU), NAFTA (the North American Free Trade Area), the ASEAN (the Association of South East Asian Nations) region and MERCOSUR (the Southern Cone countries). In these new institutional environments, the increasing international mobility of production factors means that the geography of production becomes much more complex with firm locations no longer definable simply according to their nationality. As country borders become increasingly permeable to factor flows, competition for industrial investment increasingly takes place at the level of the region or the city rather than at the level of the nation. For the analysis of these issues, traditional trade arguments based on factor proportions assumptions become much less relevant. Our insights must therefore be motivated by more appropriate analytical and empirical approaches 
specifically tailored to location questions at these more particular geographical and sectoral levels.

A range of analytical approaches can be adopted in attempting to understand the economics of industrial location behaviour. Some approaches focus on the behaviour of the individual firm in theory, and investigate the microeconomic conditions determining a firm's spatial behaviour. These types of models have a long tradition going back to Alfred Weber and Leon Moses. Other approaches, following the work of Christaller and Lösch, and more recently, of Krugman and Fujita, focus on the relationship between industrial location behaviour and the development of systems of cities or urban hierarchies. The aim here has been to understand the general equilibrium conditions governing the spatial distribution of industrial activities at the level of the aggregate economy as a whole. Over the last four decades most of the developments in these two broad analytical approaches have taken place within the fields of regional science and urban economics.

At the same time, the fields of international business and management science have developed their own analytical traditions to gain an understanding of the location behaviour of industrial activities. The analytical focus of these traditions has been on the behaviour of multinational and multiplant firms. In particular, the emphasis here is primarily on the relationships between a firm's spatial investment behaviour, its corporate organization, and how it uses its proprietary information and acquires new information in order to respond to and influence its competitive environment in the best way.

The final appraoch that provides insights into the location behaviour of firms and industries owes more to traditional geographical lines of inquiry. The aim in this field has been to integrate the various strands of the literature in order to appreciate the influence of the local economic environment on a firm and its spatial behaviour.

Each of these different analytical traditions provides us with different insights into the nature of, and the factors which influence, industrial location behaviour. The aim of this book is therefore to provide a broad analytical perspective on the range of approaches at our disposal when considering industrial location issues. It is not our intention to produce a synthesis of these different approaches, but rather to indicate how they can be used to further our understanding of different location economics issues. In order to do this, each of the following chapters provides a state-of-the-art analysis of how particular industrial location questions are addressed by each analytical tradition. The various theoretical methods employed are discussed in detail and the empirics associated with these approaches are presented in order to explain both what we do, and also currently do not, know about location issues. One of the overriding themes which emerges from these chapters is that although many of the different analytical traditions arose largely 
independently, many of the questions addressed and issues discussed are beginning to converge across these traditions. Each analytical approach provides insights which contribute to the development of each of the other approaches. Thus it would be wrong to view these different approaches as being in competition with each other. The same question can often be addressed from a variety of different perspectives. Therefore we should consider these different approaches as complementary to each other, and use all the analytical resources at our disposal better to understand the variety of economic issues which govern industrial location behaviour.

The book is divided into three parts. These three chapter groupings are arranged according to the types of industrial location issues considered, and each grouping cuts across different analytical approaches to some extent. The organization of the book therefore specifically reflects the fact that different approaches can throw new light on the same issue or question. The first part of the book, entitled Analytical Approaches to Industrial Location, contains four chapters, each of which discusses a particular theoretical and analytical approach to the question of industrial location behaviour and the spatial distribution of activities. The aim of this section is to indicate the different types of analytical questions addressed by location theorists, and to present a range of analytical techniques adopted by researchers. In the first chapter Philip McCann reviews the range of microeconomic location-production models available. These provide us with analytical insights into the spatial characteristics of firms, and, in particular, into the relationships between firm location behaviour, the distance-transactions costs of goods shipments, and microeconomic production function characteristics. In Chapter 2, John Parr reviews the range of classical central place models describing the spatial organization of the aggregate urban system on the basis of firm demand and cost functions, and indicates the extent to which many of these classical insights are still valid for current research. In Chapter 3 Dirk Stelder analyses the behaviour of central place models characterized by the recent 'new economic geography' literature, and tests the outcomes of these models in two-dimensional space. This exercise allows us to consider the appropriateness of these models as a description of observed reality and critically to examine how such models must be interpreted. Finally, in Chapter 4, Piet Pellenbarg, Leo van Wissen and Jouke van Dijk survey the literature on the behavioural and demographic approaches to firm migration analysis, and discuss the extent to which such analytical approaches depend on data availability and survey techniques.

The second part of the book, entitled Cities and Industrial Clusters, contains four chapters, each of which discusses characteristics of industrial clustering and the growth and development of urban areas. The aim of this section is indicate what we know about the nature, variety and characteristics 
of urban centres and industrial clusters. In Chapter 5, Gilles Duranton and Diego Puga survey our current empirical and theoretical understanding of the distribution of industrial activities across urban centres. In particular they focus on the question of the varieties of activities located in cities, and how these varieties themselves differ across different types of urban centres. In Chapter 6, Ian Gordon critically examines the relationship between the role played by dominant urban centres and the processes of globalization. While some of the globalization literature is seen to be rather non-analytical, it can be argued that such dominant cities do play a role in mediating global social changes, beyond what would be described by a systems view of urban hierarchy growth. In Chapter 7 Michael Steiner reviews the currently popular notion of 'industrial clusters', and argues that because this analytical concept is rather ambiguous at present, the resulting public policy debates can be somewhat inconclusive. However, the argument here is that a careful consideration of the institutional context of these notions can provide public policy with some workable frameworks. In Chapter 8, Edward Feser and Stuart Sweeney empirically investigate the nature of industrial clusters at the metropolitan level by examining the spatial characteristics of industrial linkages. Their results from the USA indicate a large amount of variability in the clustering behaviour on the part of different industries, and suggest that the dynamics of individual industries must be explicitly investigated as part of any examination of industrial clustering.

The third part of the book, entitled Multinational Firms and Location Behaviour, contains three chapters. The focus of these is the factors that influence the location behaviour of multiplant and multinational firms. The aim of this part of the book is to provide an understanding of the types of organizational, information and decision-making issues which govern the location decision of multiplant and multinational firms. Within the corporate and organizational and international business literature, these issues are viewed as contributing to the overall strategic investment behaviour of the firm, of which the location decision is one particular outcome. In Chapter 9, Ram Mudambi discusses the international business approach to locational issues, and explains how these approaches have developed over recent years. Many of the insights from other fields have contributed to new developments in the international business and strategic management literature, and these disciplines in turn now have much to say regarding geography and location issues. In Chapter 10, John Cantwell and Simona Iammarino discuss the questions of local information spillovers, and explain how the localization of information may provide different regions with different advantages in terms of the attraction of different types of investments. Drawing on observations from European regions, they explain how evidence gleaned from patent citations can be used to identify the relationships between the location of multinational investments 
and the nature and performance of local and regional economies. Finally, in Chapter 11, Tomokazu Arita and Philip McCann discuss the relationship between the geography of production and the organizational structures of multiplant and multinational firms. The focus of their analysis is the global semiconductor industry, and by comparing Japanese firms with their US counterparts, they show that simplistic analytical conclusions regarding the nature of industrial clusters cannot be made without considering organizational issues.

The intention of the book is to provide the reader with both a broad and a deep understanding of the issues underlying industrial location economics. The complexity of the issues involved can be appreciated by the variety of different approaches required in order to discuss them. The 11 chapters of this book provide insights into these various approaches. By reading these chapters both individually and from the perspective of the whole book, we can begin to understand the extent to which the different aspects of industrial location behaviour can be captured by each of the particular analytical and empirical methodologies.

I would like to thank two groups of people. First, I wish to acknowledge each of the contributors to this book. Every chapter is a major piece of research in its own right, and I am extremely grateful to the authors for their scholarly contributions. Second, I am very grateful to Dymphna Evans and the editorial team at Edward Elgar for their expertise and continued commitment to this project. 
Philip McCann - 9781781950746 